\title{
Elastic buckling of steel columns under axial compression
}

\author{
Mehmet Avcar \\ Civil Engineering Department, Suleyman Demirel University, Isparta, Turkey \\ Email address: \\ mehmetavcar@sdu.edu.tr
}

To cite this article:

Mehmet Avcar. Elastic Buckling of Steel Columns Under Axial Compression. American Journal of Civil Engineering.

Vol. 2, No. 3, 2014, pp. 102-108. doi: 10.11648/j.ajce.20140203.17

\begin{abstract}
In the present study elastic buckling of steel columns with three different cross sections, i.e. square, rectangle and circle cross sections, and two different boundary conditions, i.e. fixed-free(F-F) and pinned-pinned (P-P) boundary conditions, under axial compression has been investigated. At first, the basic equations of the problem have been given. Then solutions are found and the effects of the boundary conditions, cross sections, slenderness ratios on the buckling loads of the steel columns have been discussed. For the solution of the problem not only numerical computations have been performed but also finite element modeling (FEM) has been employed. For the validation of the present study, the results of numerical computations have been compared with the results of FEM, and a very good agreement has been achieved.
\end{abstract}

Keywords: Column, Elastic Buckling, Finite Element Modeling

\section{Introduction}

Steel is an alloy of iron, with carbon, which may contribute up to $2.1 \%$ of its weight, it can be used either separately or combined with other materials. Its popularity comes from the facts that; it has great strength and good ductility, it can be manufactured easily, and it is a relatively cheap, as well as the ultimate recyclable material [1].

Buckling behavior can be described as bending of a structure under axial compressive load. As it is well known, columns are the slender structural members that support the axial compressive loads. If the compressive load excessive, a column may fail by structural instability called buckling. Hence, the problem of buckling of steel columns is very important issue. Underestimation of this effect may lead to disastrous results or unjustified factors of safety [2]. The pioneer experiments on the buckling of bars under centrally compression, were performed by Musschenbroek [3]. And then Euler [4] investigated the elastic stability of a centrally loaded structures and given a formula for buckling of columns. Euler's formula reckon as the failure of a column stems from the stresses induced by sidewise bending only. This assumption is valid for long columns only, because the failure which occurs in short and medium columns stems from the combination of direct compression and bending. Euler developments of columns had been reviewed by Bleich [5] and Timoshenko [6]. Elastic beam-columns were examined by Timoshenko and Gere [7]. In the monograph of Brush and Almroth [8], the buckling of bars, plates and shells was investigated. In the study of Shrivastava [9] the elastic buckling of columns under varying axial force was examined. Reissner [10] presented a study on the buckling of columns. Historic highlights and milestones covering the development and application of the Euler formula for buckling strength of a geometrically perfect column together with modifications for inelastic behavior was given in the research of Johnston [11]. The fundamental concepts and on the methodology developed through the years to solve structural stability problems were given in the monograph of Simitses [12]. The subject of buckling of columns maintains its importance nowadays, and numerous studies have been performed on this topic with considering different boundary conditions, effects, shapes, and methods [13-34].

The one of the important problems arisen in the columns is determining its optimal shape against buckling. Namely, the strongest column i.e., the column including the largest critical buckling load. Earlier investigation on this issue was given in the study of Keller [35]. And then several studies were performed on this topic [36-50].

As one can see from the open literature, column buckling is an important and actual problem for researchers and engineers. In the present study elastic buckling of steel columns with different cross sections, lengths and F-F and P-P conditions, subjected to axial compressive load is 
addressed. The results of numerical computations and finite element model are compared and the differences between them are analyzed. Furthermore, the influences of slenderness ratio, cross section and boundary conditions on the buckling behaviors of columns are examined in detail.

\section{Basic Equations}

Consider an elastic column of length L loaded by an axial compressive load $\mathrm{P}$ with the action line coinciding with the $\mathrm{z}$ axis of a rectangular coordinate system Ozx with (F-F) and (P-P) boundary conditions respectively as shown in Figure 1(a-b). In here, dashed lines denote the buckled shape of the columns. Furthermore, the three different cross sections of the column have been shown in Figure 1(c).

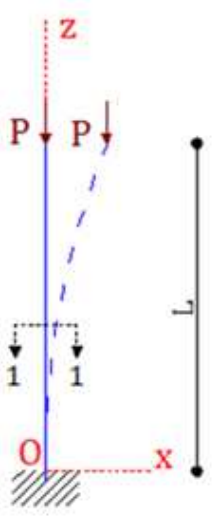

a)

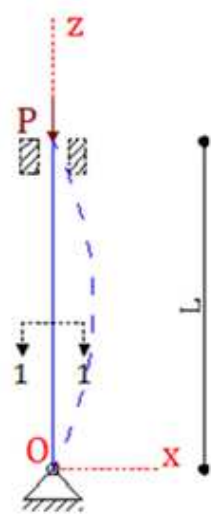

b)
1-1 Cross Sections
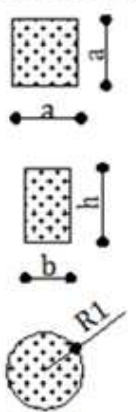

c)
Figure 1. Geometry of column under axial compression is

The governing equation for the buckling of such columns

$$
\mathrm{EI} \frac{\mathrm{d}^{4} \mathrm{u}}{\mathrm{dz^{4 }}}+\mathrm{P}_{\mathrm{cr}} \frac{\mathrm{d}^{2} \mathrm{u}}{\mathrm{dz^{2 }}}=0
$$

where E is the Young's modulus of the column, I is the area moment of inertia of the column cross section, and $u$ is the transverse displacement.

As Eq. (1) is modified the following equation yields:

$$
\frac{d^{4} u}{d z^{4}}+k^{2} \frac{d^{2} u}{d z^{2}}=0
$$

where the following definition applies

$$
\mathrm{k}^{2}=\frac{\mathrm{P}}{\mathrm{EI}}
$$

The general solution of Equation (2) as follows:

$$
\mathrm{u}(\mathrm{z})=\mathrm{C}_{1} \sin \mathrm{kz}+\mathrm{C}_{2} \cos \mathrm{kz}+\mathrm{C}_{3} \mathrm{z}+\mathrm{C}_{4}
$$

where are $\mathrm{C}_{1}, \mathrm{C}_{2}, \mathrm{C}_{3}$ and $\mathrm{C}_{4}$ coefficients and can be identified with boundary conditions.

\section{Solution of the Basic Equations}

\subsection{Particular Solution for Fixed-Free (F-F) Column}

The boundary conditions satisfies the F-F column as follows:

$$
\begin{gathered}
\left.\mathrm{u}\right|_{\mathrm{z}=0}=0 \text { and }\left.\frac{\mathrm{du}}{\mathrm{dz}}\right|_{\mathrm{z}=0}=0 \\
\left.\frac{\mathrm{d}^{2} \mathrm{u}}{\mathrm{dz}^{2}}\right|_{\mathrm{z}=\mathrm{L}}=0 \text { and }\left.\left(\frac{\mathrm{d}^{3} \mathrm{u}}{\mathrm{dz}^{3}}+\mathrm{k}^{2} \frac{\mathrm{du}}{\mathrm{dz}}\right)\right|_{\mathrm{z}=\mathrm{L}}=0
\end{gathered}
$$

Substituting the Eqs. (5)-(6) into (4) and after some mathematical rearrangements, the determinant of coefficient matrix and its solution gotten as follows:

$$
\begin{aligned}
& \left|\begin{array}{llll}
0 & 1 & 0 & 1 \\
k & 0 & 1 & 0 \\
-k^{2} \sin (k L) & -k^{2} \cos (k L) & 0 & 0 \\
0 & 0 & k^{2} & 0
\end{array}\right|=k^{5} \cos (k L)=0 \\
& k L=(2 n+1) \frac{\pi}{2} \\
& k^{2}=(2 n+1)^{2}\left(\frac{\pi}{2 L}\right)^{2} \\
& \frac{P}{E I}=(2 n+1)^{2}\left(\frac{\pi}{2 L}\right)^{2} \\
& P=(2 n+1)^{2}\left(\frac{\pi}{2 L}\right)^{2} E I, n=0,1,2, \ldots
\end{aligned}
$$

Consequently, the critical buckling load occurs when $\mathrm{n}=0$ and we get [4]:

$$
\mathrm{P}_{\mathrm{cr}}=\left(\frac{\pi}{2 \mathrm{~L}}\right)^{2} \mathrm{EI}_{\mathrm{min}}
$$

where $I_{\min }$ is the minimum area moment of inertia of the column cross section.

\subsection{Particular Solution for Pinned-Pinned (P-P) Column}

The boundary conditions satisfies the P-P column as follows:

$$
\begin{aligned}
& \left.\mathrm{u}\right|_{\mathrm{z}=0}=0 \text { and } \frac{\mathrm{d}^{2} \mathrm{u}}{\left.\mathrm{dz}^{2}\right|_{\mathrm{z}=0}=0} \\
& \left.\mathrm{u}\right|_{\mathrm{z}=\mathrm{L}}=0 \text { and }\left.\frac{\mathrm{d}^{2} \mathrm{u}}{\mathrm{dz}^{2}}\right|_{\mathrm{z}=\mathrm{L}}=0
\end{aligned}
$$


Substituting Eqs. (13)-(14) into (4), and after some mathematical rearrangements, the determinant of coefficient matrix and its solution found as follows:

$$
\begin{gathered}
\begin{array}{llll}
0 & 1 & 0 & 1 \\
0 & -k^{2} & 0 & 0 \\
\sin (\mathrm{kL}) & \cos (\mathrm{kL}) & \mathrm{L} & 1 \\
-\mathrm{k}^{2} \sin (\mathrm{kL}) & -\mathrm{k}^{2} \cos (\mathrm{kL}) & 0 & 0
\end{array} \mid=-\mathrm{k}^{4} \mathrm{~L} \sin (\mathrm{kL})=0 \\
\mathrm{~kL}=\mathrm{n} \pi \\
\mathrm{k}^{2}=\mathrm{n}^{2}\left(\frac{\pi}{\mathrm{L}}\right)^{2} \\
\frac{\mathrm{P}}{\mathrm{EI}}=\mathrm{n}^{2}\left(\frac{\pi}{\mathrm{L}}\right)^{2} \\
\mathrm{P}=\mathrm{n}^{2}\left(\frac{\pi}{\mathrm{L}}\right)^{2} \mathrm{EI}, \mathrm{n}=1,2, \ldots
\end{gathered}
$$

Consequently, the critical buckling load occurs when $\mathrm{n}=1$ and we get $[4]$ :

$$
\mathrm{P}_{\mathrm{cr}}=\left(\frac{\pi}{\mathrm{L}}\right)^{2} \mathrm{EI} \mathrm{I}_{\min }
$$

\subsection{General Formulation for F-F and P-P Columns}

The buckling load can be expressed as the following general form also:

$$
\mathrm{P}_{\mathrm{cr}}=\frac{\pi^{2} \mathrm{EI}_{\mathrm{min}}}{\mathrm{L}_{\mathrm{eff}}^{2}}
$$

where, $\mathrm{L}_{\text {eff }}$ is the effective length of column, and $\mathrm{L}_{\text {eff }}=2 \mathrm{~L} ; \mathrm{L}_{\mathrm{eff}}=\mathrm{L}$ for $\mathrm{F}-\mathrm{F}$ and $\mathrm{P}-\mathrm{P}$ columns, respectively.

\section{Finite Element Modeling of Problem}

The finite element modeling of the problem is very important step to achieve accurate results. For the finite element modeling a computer program called ANSYS has been employed [51].

Beam element is used in the modeling and finite element mesh of column is modeled using appropriate nodes and elements depending on length and cross section of the column with sizing and bias factor. The sample of mesh design of the column is shown in Figure 2.

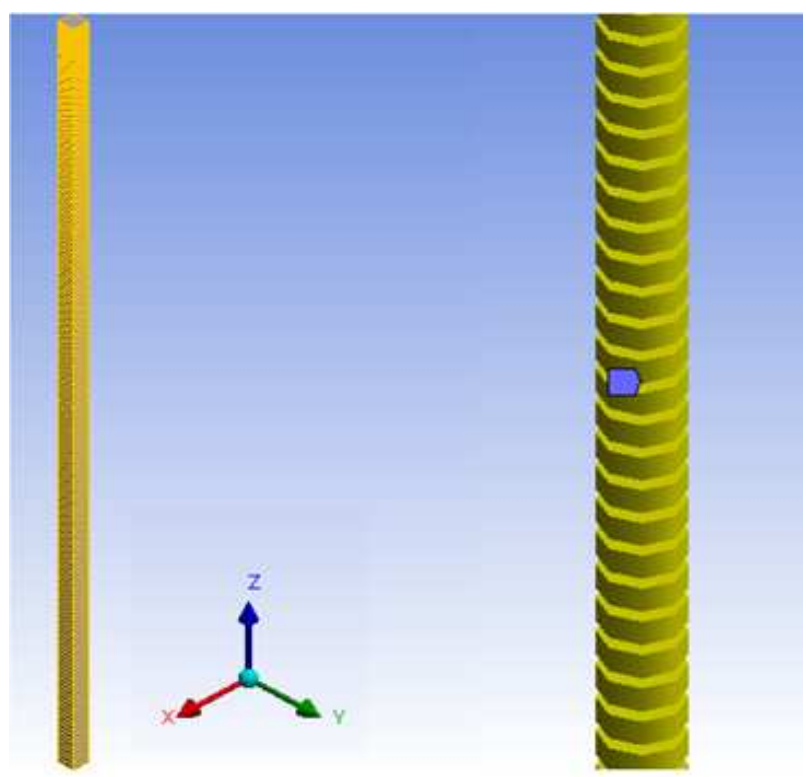

Figure 2. Mesh design of the column

\section{Numerical Results and Discussion}

In this section, five studies have been performed for investigating the buckling behaviors of the steel columns with different geometries and boundary conditions.

Study 1 . In Table 1 variations of the buckling loads versus length, which are obtained from FEM and the formula of Euler [4], for steel columns with three different cross sections and F-F ends are given. As the buckling loads of FEM, $\mathrm{P}_{\text {crFEM }}$, are compared with the results of the formula of Euler [4], $\mathrm{P}_{\text {crEuler }}$, the difference between them varies from $0.01 \%$ to $0.29 \%$, namely a very good agreement is achieved, and this shows the accuracy of the present finite element model. Where the following expression is used for calculation of percentages $\left(\frac{\mathrm{P}_{\text {crEuler }}-\mathrm{P}_{\text {crFEM }}}{\mathrm{P}_{\text {crEuler }}}\right) \times 100$. Besides, the differences between $\mathrm{P}_{\text {crFEM }}$ and $\mathrm{P}_{\text {crEuler }}$ are, $0.03 \% ; 0.03 \% ; 0.02 \% ; 0.02 \%$ in square cross section, $0.01 \%$; $0.01 \% ; 0.01 \% ; 0.01 \%$ in rectangle cross section, $0.29 \%$; $0.29 \% ; 0.29 \% ; 0.28 \%$ in circle cross section for $\mathrm{L}=2750 ; 3000 ; 3250 ; 3500 \mathrm{~mm}$ respectively. One can see from the above results that the highest differences between FEM and Euler [4] occur in the circle cross section, and the lowest differences between FEM and Euler [4] occur in rectangle cross section.

For examining the efficient shape of column against buckling, the areas of all cross sections are fixed, i.e. $\mathrm{A}=3600 \mathrm{~mm}^{2}$, for F-F steel column with square, rectangle and circle cross sections. As the appropriate columns are compared with each other, namely columns whose volumes are equal, the differences between the buckling loads of square cross section and rectangle cross section are approximately $55.55 \%$ for $\mathrm{P}_{\text {crFEM }}$; the differences between the buckling loads of square cross section and circle cross 
section are nearly $4.72 \%$ for $\mathrm{P}_{\text {crFEM }}$; the differences between the buckling loads of circle cross section and rectangle cross section are approximately $53.35 \%$ for $\mathrm{P}_{\text {crFEM }}$. Here the following expressions are used for calculation of the percentages $\left(\frac{\mathrm{P}_{\text {crSquare }}-\mathrm{P}_{\text {crRect }}}{\mathrm{P}_{\text {crSquare }}}\right) \times 100$,
$\left(\frac{\mathrm{P}_{\text {crSquare }}-\mathrm{P}_{\text {crCircle }}}{\mathrm{P}_{\text {crSquare }}}\right) \times 100$ and $\left(\frac{\mathrm{P}_{\text {crCircle }}-\mathrm{P}_{\text {crRect }}}{\mathrm{P}_{\text {crCircle }}}\right) \times 100$. Consequently, it is observed that, the most efficient shape of column against buckling is square cross section, for investigated problem, due to highest buckling loads are obtained in this cross section. In addition, the lowest buckling loads are found in rectangle cross section, and so it is the least efficient shape of column against buckling, for examined problem.

Table 1. The variations of buckling loads of F-F steel column with three different equivalent cross sections versus length. $\left(\mathrm{E}=2 \times 10^{5} \mathrm{MPa}, \mathrm{A}=3600 \mathrm{~mm}^{2}\right)$

\begin{tabular}{ccccccc}
\hline & \multicolumn{4}{c}{$\mathrm{P}_{\text {cr }}(\mathrm{kN})$} \\
$\mathrm{L}(\mathrm{mm})$ & \multicolumn{2}{c}{ Square F-F $(\mathrm{a}=60 \mathrm{~mm})$} & Rectangle F-F $\left(\begin{array}{l}\mathrm{b}=90 \mathrm{~mm} \\
\mathrm{~h}=40 \mathrm{~mm}\end{array}\right)$ & \multicolumn{2}{c}{ Circle F-F $(\mathrm{R} 1=33.855 \mathrm{~mm})$} \\
& FEM & Euler [4] & FEM & Euler [4] & FEM & Euler [4] \\
\hline 2750 & 70.452 & 70.474 & 31.318 & 31.322 & 67.129 & 67.326 \\
3000 & 59.202 & 59.218 & 26.316 & 26.319 & 56.409 & 56.573 \\
3250 & 50.447 & 50.458 & 22.423 & 22.426 & 48.066 & 48.204 \\
3500 & 43.499 & 43.507 & 19.335 & 19.336 & 41.446 & 41.564 \\
\hline
\end{tabular}

Study 2. In Figure 3 variations of the buckling loads of FEM for steel columns with three different equivalent cross sections versus length under F-F boundary conditions are presented.

One of the dominant parameter acting on the elastic buckling of the column is slenderness ratio, $\lambda$ :

$$
\lambda=\frac{\mathrm{L}_{\mathrm{eff}}}{\mathrm{i}}
$$

where $i$ is the radius gyration and the following definition applies:

$$
i=\sqrt{\frac{I_{\text {min }}}{A}}
$$

The slenderness ratios of steel column are computed as follows, $\lambda=318 ; 346 ; 375 ; 404$ for square cross section; $\lambda=476 ; 520 ; 563 ; 606$ for rectangle cross section and $\lambda=325 ; 354 ; 384 ; 414$ for circle cross section, for $\mathrm{L}=2750 ; 3000 ; 3250 ; 3500 \mathrm{~mm}$ respectively, under $\mathrm{F}-\mathrm{F}$ boundary conditions. As it is seen from the above results that the square cross section has the lowest slenderness ratios, and the rectangle cross section has the highest slenderness ratios for investigated problem and note that the slenderness ratio increase with the increase of the length of the column. In addition it is observed that the buckling loads decrease with the increase of slenderness ratio, in all cross sections. The effect of the variation of the slenderness ratio on the buckling loads are $15.97 \% ; 28.40 \% ; 38.26 \%$ for square cross section, $15.98 \% ; 28.40 \% ; 38.26 \%$ for rectangle cross section, $15.97 \% ; 28.40 \% ; 38.26 \%$ for circle cross section. Consequently, it is observed that the effects of the variation of slenderness ratios on the buckling loads increase with the increase of the length of the column and remains in an almost same interval for all cross sections, under F-F boundary conditions.

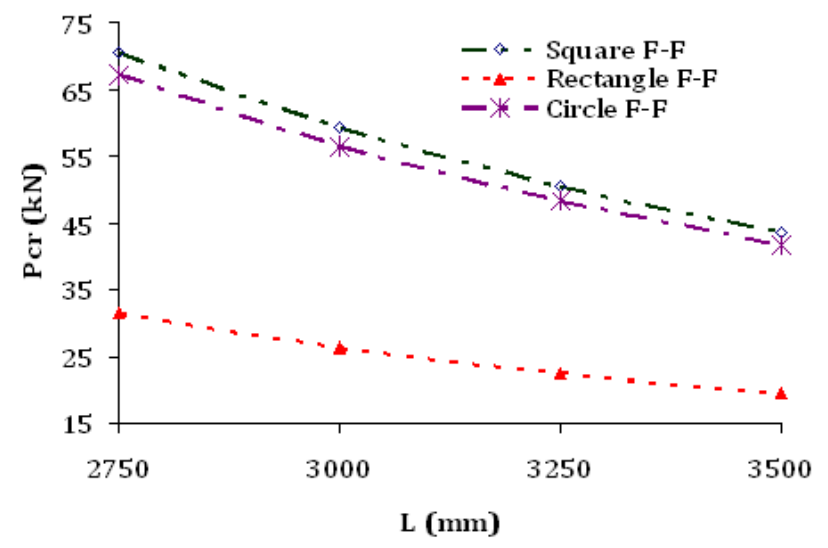

Figure 3. Variations of the buckling loads of FEM for steel columns with three different equivalent cross sections versus length under F-F boundary conditions ( $\mathrm{E}=2 \times 10^{5} \mathrm{MPa}, \mathrm{A}=3600 \mathrm{~mm}^{2}$ )

Study 3. In Table 2 variations of the buckling loads versus length, which are obtained from FEM and the formula of Euler [4], for steel columns with three different cross sections and $\mathrm{P}-\mathrm{P}$ ends are tabulated. The differences between $\mathrm{P}_{\text {crFEM }}$ and $\mathrm{P}_{\text {crEuler }}$ are, $0.12 \% ; 0.10 \% ; 0.09 \% ; 0.07 \%$ in square cross section , $0.05 \% ; 0.04 \% ; 0.04 \% ; 0.03 \%$ in rectangle cross section, $0.38 \% ; 0.30 \% ; 0.29 \% ; 0.27 \%$ in circle cross section for $\mathrm{L}=2750 ; 3000 ; 3250 ; 3500 \mathrm{~mm}$ respectively. One can see from above the results that the highest differences between FEM and Euler [4] arise in the circle cross section, and the lowest differences between FEM and Euler [4] arise in rectangle cross section under P-P boundary conditions. 
For investigating the efficient shape of column against buckling, the areas of all cross sections are fixed, i.e. $A=3600 \mathrm{~mm}^{2}$, for columns pinned both ends with square, rectangle and circle cross sections. As the convenient columns are compared with each other, the differences between the buckling loads of square cross section and rectangle cross section are nearly $55.56 \%$ for $\mathrm{P}_{\text {crFEM}}$; the differences between the buckling loads of square cross section and circle cross section are nearly $4.47 \%$ for $\mathrm{P}_{\text {crFEM }}$; the differences between the buckling loads of circle cross section and rectangle cross section are $53.48 \%$ for $\mathrm{P}_{\text {crFEM }}$. Therefore, it is concluded that the most strongest shape of column against buckling is square cross section, as well as the least efficient shape of column against buckling is rectangle cross section for columns pinned both ends in examined problem.

Table 2. The variations of buckling loads of P-P steel column with three different equivalent cross sections versus length. $\left(\mathrm{E}=2 \times 10^{5} \mathrm{MPa}, \mathrm{A}=3600 \mathrm{~mm}^{2}\right)$

\begin{tabular}{|c|c|c|c|c|c|c|}
\hline \multirow[t]{2}{*}{$\mathrm{L}(\mathrm{mm})$} & \multicolumn{4}{|c|}{$\begin{array}{c}\mathrm{P}_{\mathrm{cr}}(\mathrm{kN}) \\
\text { Rectangle P-P } \\
\left(\begin{array}{l}\mathrm{b}=90 \mathrm{~mm} \\
\mathrm{~h}=40 \mathrm{~mm}\end{array}\right)\end{array}$} & \multicolumn{2}{|c|}{ Circle P-P ( R1 $=33.855 \mathrm{~mm})$} \\
\hline & FEM & Euler [4] & FEM & Euler [4] & FEM & Euler [4] \\
\hline 2750 & 281.550 & 281.895 & 125.122 & 125.287 & 268.290 & 269.306 \\
\hline 3000 & 236.630 & 236.871 & 105.230 & 105.276 & 225.610 & 226.292 \\
\hline 3250 & 201.650 & 201.830 & 89.668 & 89.702 & 192.260 & 192.816 \\
\hline 3500 & 173.900 & 174.027 & 77.320 & 77.345 & 165.80 & 166.255 \\
\hline
\end{tabular}

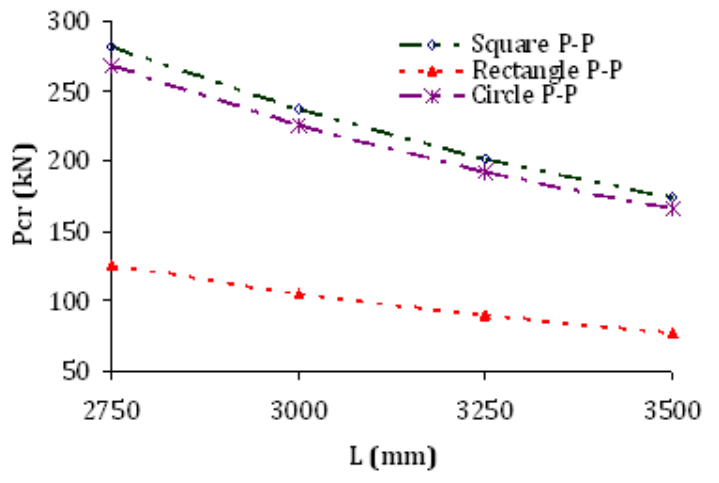

Figure 4. Variations of the buckling loads of FEM for columns with three different equivalent cross sections versus length under P-P boundary conditions $\left(\mathrm{E}=2 \times 10^{5} \mathrm{MPa}, \mathrm{A}=3600 \mathrm{~mm}^{2}\right.$ )

Study 4. In Figure 4 variations of the buckling loads of FEM for steel columns with three different equivalent cross sections versus length with P-P ends are presented. The slenderness ratios of the steel column pinned both ends are computed as follows: $\lambda=159 ; 173 ; 188 ; 202$ for square cross section; $\lambda=238 ; 260 ; 281 ; 303$ for rectangle cross section and $\lambda=162 ; 177 ; 192 ; 207$ for circle cross section, for $\mathrm{L}=2750 ; 3000 ; 3250 ; 3500 \mathrm{~mm}$, respectively. It is seen from the above results that the square cross section has the lowest slenderness ratios, and the rectangle cross section has the highest slenderness ratios for investigated problem. In addition it is observed that the buckling loads decrease with the increase of slenderness ratio, in all cross sections. The effect of the variation of the slenderness ratio on the buckling loads are $15.96 \% ; 28.38 \% ; 38.23 \%$ for square cross section, $15.96 \% ; 28.39 \% ; 38.25 \%$ for rectangle cross section, $15.91 \% ; 28.34 \% ; 38.20 \%$ for circle cross section. Consequently, it is found that the effects of the variation of slenderness ratios on the buckling loads increase with the increase of the length of the column and remains in an almost same interval for all cross sections under P-P boundary conditions.

Study 5. As the buckling loads of F-F and P-P steel columns for $\mathrm{L}=2750 ; 3000 ; 3250 ; 3500 \mathrm{~mm}$, which are shown in Figs. 3-4, respectively, are compared in each other, it is seen that the buckling loads of P-P columns are higher than those for F-F columns. In addition, the boundary conditions have a constant influence on the buckling loads in all cross sections, approximately $75 \%$. Where the following expressions are used for calculation of the percentages $\left(\frac{\mathrm{P}_{\text {crP-P }}-\mathrm{P}_{\text {crF-F }}}{\mathrm{P}_{\text {crP-P }}}\right) \times 100$. Consequently, it is observed that columns with P-P conditions have more resistant against buckling than F-F columns.

\section{Conclusion}

In the present work elastic buckling of steel columns with three different cross sections and F-F and P-P boundary conditions under axial compressive load is studied. The effects of the boundary conditions, cross sections, slenderness ratios on the buckling load of the steel column have been discussed. Numerical computations have been performed, and FEM has been employed for the solution of the problem. And briefly the following results are obtained for the investigated problem:

- $\quad$ The highest differences between FEM and numerical computation occur in the circle cross section, and the lowest differences between FEM and numerical computation arise in rectangle cross section, in both of F-F and P-P boundary conditions. 
- $\quad$ The most efficient shape of column against buckling is square cross section and the least efficient shape of column against buckling is rectangle cross section, in both of F-F and P-P boundary conditions.

- The square cross section has the lowest slenderness ratios, and the rectangle cross section has the highest slenderness ratios, in both of F-F and P-P boundary conditions.

- The effects of the variation of slenderness ratios on the buckling loads increase with the increase of the length of the column and remains in an almost same interval for all cross sections, in both of F-F and P-P boundary conditions.

- As the convenient buckling loads of F-F and P-P columns are compared, the buckling loads of P-P column is higher than F-F column.

\section{References}

[1] Gardner, L. (2005), "The use of stainless steel in structures", Progress in Structural Engineering and Materials, Vol. 7, No. 2, pp. 45-55.

[2] Elishakoff, I. (2001), "Columns", Encyclopedia of Vibration, pp. 236-243.

[3] Musschenbroek P. Van. (1729), "Introductio da Cohaerentiam Corporum Firmorum", Lugduni.

[4] Euler, L. (1759), "On the strength of columns" , Academy Royal Society Belles Lettres Berlin Memoires 13 p. 252.

[5] Bleich, F. (1952), Buckling Strength of Metal Structures, Eng. Soc. Monograph, McGraw-Hill, New York.

[6] Timoshenko, S.P. (1953), History of Strength of Materials, McGraw-Hill, New York

[7] Timoshenko, S. P. and Gere, J. M. (1961), Theory of Elastic Stability, McGraw-Hill, New York.

[8] Brush, D.O. and Almroth, B.O. (1975), Buckling of Bars, Plates, and Shells, McGraw-Hill, New York.

[9] Shrivastava, S.C. (1980), "Elastic buckling of a column under varying axial force", Engineering Journal-American Institute of Steel Construction, Vol. 17, No. 1, pp. 19-21.

[10] Reissner, E., (1982), "Some remarks on the problem of column buckling", Ingenieur-Archiv, Vol. 52, No. 1-2, pp. 115-119.

[11] Johnston, B.G., (1983), "Column buckling theory - historic highlights", Journal of Structural Engineering-ASCE, Vol. 109, No. 9, pp. 2086-2096.

[12] Simitses, G.J., (1986), An Introduction to the Elastic Stability of Structures, Krieger, Malabar, FL.

[13] Ings, N.L. and Trahair, N.S., (1987), "Beam and column buckling under directed loading", Journal of Structural Engineering ASCE, Vol. 113, No.6, pp. 1251-1263.

[14] Bert, C.W., (1990), "Effect of axial compressibility on buckling of columns", Journal of Engineering
Mechanics-ASCE, Vol. 116, No. 3, 728-732.

[15] Gjelsvik, A., (1991), "Stability of built-up columns", Journal of Engineering Mechanics- ASCE, Vol. 117, No. 6, pp. 1331-1345.

[16] Vaziri, H.H. and Xie, J., (1992), "Buckling of columns under Variably Distributed Axial Loads", Computers \& Structures, Vol. 45, No. 3, pp. 505-509.

[17] Mukherjee, A., Deshpande, J.M. and Anmala, J (1996), "Prediction of buckling load of columns using artificial neural networks", Journal of Structural Engineering-ASCE, Vol. 122, No. 11, pp. 1385-1387

[18] Xie, Y.J., Ning, Q.H. and Chen, M.L., (1998), "The approximate analytical solution for the buckling loads of a thin-walled box column with variable cross-section", Applied Mathematics And Mechanics-English, Vol. 19, No. 5, pp. 445-456.

[19] Elishakoff, I. and Rollot, O., (1999), "New Closed-Form Solutions For Buckling Of A Variable Stiffness Column By Mathematica (R)", Journal of Sound And Vibration, Vol. 224, No. 1, pp. 172-182.

[20] Schafer, B.W., (2002), "Local, distortional, and Euler buckling of thin-walled columns", Journal Of Structural Engineering-ASCE, Vol. 128, No. 3, pp. 289-299.

[21] Rasmussen, K.J.R. and Trahair, N.S., (2005), "Exact and approximate solutions for the flexural buckling of columns with oblique rotational end restraints", Thin-Walled Structures, Vol. 43, No. 3, pp. 411-426.

[22] Jang, H.J., Seo, S.Y. and Yang, Y.S., (2006) "Buckling behavior of stainless steel square hollow columns under eccentric loadings", Structural Engineering and Mechanics, Vol. 23, No. 5, pp. 563-577.

[23] Ellobody, E., (2007), "Buckling analysis of high strength stainless steel stiffened and unstiffened slender hollow section columns", Journal of Constructional Steel Research Vol. 63, No. 2, pp. 145-155.

[24] Chan, T.M. and Gardner, L., (2009), "Flexural buckling of elliptical hollow section columns", Journal of Structural Engineering-ASCE, Vol. 135, No. 5, pp. 546-557.

[25] Hosseini H.B. and Jafari, M.A., (2009), "Experimental evaluation of elastic critical load in batten columns", Journal of Constructional Steel Research, Vol. 65, No. 1, pp. 125-131.

[26] Darbandi, S.M., Firouz-Abadi, R.D. and Haddadpour, H., (2010), "Buckling of variable section columns under axial loading", Journal of Engineering Mechanics-ASCE, Vol. 136, No. 4, pp. 472-476.

[27] Gross, D., Schröder, J., Bonet, J., Hauger, W. and Wall W.A., (2011), "Buckling of Bars", Engineering Mechanics Vol. 2, pp. 287-305.

[28] Ziolkowski, A. and Imieowski, S., (2011), "Buckling and post-buckling behaviour of prismatic aluminium columns submitted to a series of compressive loads", Experimental Mechanics, Vol. 51, No. 8, pp. 1335-1345.

[29] Huang, Y. and Li, X.-F., (2012), "An analytic approach for exactly determining critical loads of buckling of nonuniform columns", International Journal Of Structural Stability And Dynamics, Vol. 12, No. 4, id. 1250027 
[30] Adman, R. and Saidani, M., (2013), "Elastic buckling of columns with end restraint effects", Journal of Constructional Steel Research, Vol. 87, pp. 1-5.

[31] Kumar, M. and Yadav, N., (2013), "Buckling analysis of a beam-column using multilayer perceptron neural network technique", Journal of the Franklin Institute-Engineering and Applied Mathematics, Vol. 350, No. 10, pp. 3188-3204.

[32] Longshithung, P.M. and Darunkumar, S.K., (2013), Buckling of fixed-ended lean duplex stainless steel hollow columns of square, L-, T-, and +-shaped sections under pure axial compression - A finite element study, Thin-Walled Structures, Vol. 63, pp.106-116.

[33] Tekeli, H., Korkmaz, K.A., Demir, F. and Carhoglu, A.I., (2014) "Comparison of critical column buckling load in regression, fuzzy logic and ANN based estimations", Journal of Intelligent and Fuzzy Systems, Vol. 26, No. 3, pp. $1077-1087$

[34] Yuan, W.B., Kim B. and Li L-Y., (2014), "Buckling of axially loaded castellated steel columns", Journal of Constructional Steel Research, Vol. 92, pp. 40-45.

[35] Keller, J.B., (1960), "The shape of the strongest column", Archive for Rational Mechanics and Analysis, Vol. 5, No.1, pp. 275-285.

[36] Yura, J.A., (1971), "Effective length of columns in unbraced frames", Engineering Journal-American Institute of Steel Construction, Vol. 8, No. 2, pp. 37-42.

[37] Olhoff, N. and Rasmussen, S.H., (1977), "On single and bimodal optimum buckling loads of clamped columns", International Journal of Solids and Structures, Vol. 13, No. 7 , pp. 605-614.

[38] Szyszkowski, W. and Watson, L.G., (1988), "Optimization of the buckling load of columns and frames", Engineering Structures, Vol. 10, No. 4, pp. 249-256.

[39] Egorov, Y.V. and Karaa, S., (1996), "On the optimal shape of a column against buckling", Comptes Rendus De L Academie Des Sciences Serie I-Mathematique, Vol. 322, No. 6, pp. 519-524.

[40] Chase, J. and Yim, M. (1999), "Optimal Stabilization of
Column Buckling", Journal of Engineering Mechanics-ASCE, Vol. 125, No. 9, pp. 987-993.

[41] Manickarajah, D., Xie, Y.M. and Steven, G.P., (2000), "Optimization of columns and frames against buckling", Computers \& Structures, Vol. 75, No. 1, pp.45-54.

[42] Maalawi, K.Y., (2002), "Buckling optimization of flexible columns", International Journal Of Solids And Structures, Vol. 39, No. 23, pp. 5865-5876.

[43] Kruzelecki, J and Smas, P., (2004), "Optimal design of simply supported columns for buckling under loading controlled by displacements", Engineering Optimization, Vol. 36, No. 6, pp. 645-658.

[44] Atanackovic, T.M., (2007), "Optimal shape of a strongest inverted column", Journal of Computational and Applied Mathematics, Vol. 203, No. 1, pp. 209-218.

[45] Jelicic, Z.D. and Atanackovic, T.M., (2007), "Optimal shape of a vertical rotating column", International Journal of Non-Linear Mechanics, Vol. 42, No. 1, pp. 172-179.

[46] Atanackovic, T.M., Novakovic, B.N. and Basara, E., (2010), "On the optimal shape of a compressed column", Theoretical Applied Mechanics, Vol.37, No.1, pp. 37-48.

[47] Krużelecki, J. and Ortwein, R., (2012), "Optimal design of clamped columns for stability under combined axial compression and torsion", Structural and Multidisciplinary Optimization, Vol.45, No. 5, pp. 729-737.

[48] Lee, B.K., Lee, T.E. and Jung, Y.S., (2012), "Numerical methods for determining strongest cantilever beam with constant volume", KSCE Journal of Civil Engineering, Vol. 16, No. 1, pp. 169-178.

[49] Kripka, M. and Martin, Z., (2013), "Cold-formed steel channel columns optimization with simulated annealing method", Structural Engineering and Mechanics, Vol. 48 No. 3, pp. 383-394.

[50] Jatav, S.K. and Datta, P.K., (2014) "Shape optimization of damaged columns subjected to conservative and non-conservative forces",International Journal of Aeronautical and Space Sciences, Vol. 15 No. 1, pp. 20-31.

[51] ANSYS ${ }^{\circledR}$ Academic Research, Release 15.0 